available data. The New Zealand study argues that in 1975 the rates of use of oral contraceptives were higher in that country than in Britain, but this does not necessarily apply to young women. By 1975 in Britain nearly $40 \%$ of sexually active single women aged under 20 were taking the pill, ${ }^{17}$ but it is not clear whether this was also true in New Zealand or Sweden.

Such data will, we hope, come from the controls in these various studies or from population surveys. We need to know not only the duration of early exposure to oral contraceptives but also the time that elapses between exposure and diagnosis. Tabulating relative risks by time since first use as these two studies have done is not enough. Nor is it helpful to standardise for duration of use of oral contraceptives as was done in the Swedish study: this might standardise out a possible latent effect. The duration of use and the time since first use are correlated with each other and with a possible latent period, but neither measures latency. A way to investigate a possible latent effect that overcomes these difficulties was described in 1981..$^{18}$

Whether or not there is a latent effect of early use of oral contraceptives on breast cancer, there are other possible reasons for the discrepancy between these two studies. The Swedish study was conducted at a time of increasing consciousness of a possible association between the pill and breast cancer, and the cases and controls were fully aware of the purpose of the study at the time of their interview. The accuracy of recall of the use of oral contraceptives, going back 20 or more years, may not have been comparable between cases and controls. Women with breast cancer have strong reasons for thinking hard about their history; controls have not. Such differences can lead to serious bias in case-control studies —enough to explain a relative risk of 2 .

On the other hand, the Swedish study matched the controls with cases very closely. In the New Zealand study the controls were not individually matched at all: adjustments were made in the analysis, and this may not be adequate when one is concerned with a rapidly changing exposure rate. In studies of this kind age is a crucial confounding variable because it influences not only the risk of breast cancer but also the risk of exposure to oral contraceptives. The popularity of oral contraceptives among young women has dramatically changed over a short time, and in current studies older women are much less likely than younger women to have been exposed to oral contraceptives at an early age. ${ }^{19}$ Because the patterns of pill use have changed so quickly adjustment within five year intervals, as was done in the New Zealand study, may be inadequate. In the Swedish study controls were the same age as each case to within a single month. Age at first birth is another important confounding variable, and in the Swedish study some controls had their first baby within two months of the corresponding case.

Finally, the types of pill used by the women in these studies may have varied. Oral contraceptive formulations vary with time and place, and the dosages of synthetic hormones have decreased appreciably over the past 20 years. If oral contraceptives are implicated in the risk of breast cancer their effect may be altered by hormone and dose as well as by duration of use and the woman's age at use. Neither of the new studies gives any indication of the types of pill used, and therefore we have no idea whether the results are relevant to our own current practice.

Nevertheless, the fact that one of these studies shows a possible association of oral contraceptives with breast cancer provides a powerful reason for trying to find out more.
Epidemiology may be a blunt tool for dissecting this complicated relation and needs to be complemented by a much better understanding of the biological effects of hormones on breast tissue. ${ }^{2021}$ Some of the outstanding questions could be investigated by collaboration between investigators with open minds. Until that happens and until other studies under way are reported the question remains open. We cannot say with any certainty that the pill used for long periods early in reproductive life is, or is not, associated with a change in the risk of breast cancer. While this uncertainty remains there is no reason to change our prescribing habits or our advice to women using the pill.

KLIM MCPHERSON

University Lecturer in Medical Statistics,

Department of Community Medicine and General Practice,

Radcliffe Infirmary,

Oxford OX2 6HE

JAMES OWEN DRIFE

Senior Lecturer in Obstetrics and Gynaecology,

University of Leicester,

Leicester LE2 7LX

1 Clavel F, Benhamou E, Sitruk-Ware R, Mauvais-Jarvis P, Flamant R. Breast cancer and oral contraceptives: a review. Contraception 1985;32:553-70.

2 Centers for Disease Control Cancer and Steroid Hormone Study. Oral contraceptives and the risk of ovarian cancer. FAMA 1983;249:1596-9.

3 Centers for Disease Control Cancer and Steroid Hormone Study. Oral contraceptives and the risk of endometrial cancer. FAMA 1983;249:1600-4.

4 Vessey MP, McPherson K, Lawless M, Yeates D. Neoplasia of the cervix uteri and contraception: a possible adverse effect of the pill. Lancet 1983;ii:930-4.

5 Drife JO. Breast development in puberty. Ann NY Acad Sci 1986;464:58-65.

6 Oka T, Yoshimura M. Paracrine regulation of mammary gland growth. Clin Endocrinol Metab 1986;15:79-97.

7 Pike MC, Henderson BE, Krailo MD, Duke A, Roy S. Breast cancer in young women and oral contraceptives: a possible modifying effect of formulation and age at use. Lancet 1983;ii:926-9.

McPherson K, Neil A, Vessey MP, Doll R. Oral contraceptives and breast cancer. Lancet $1983 ;$ ii: $1414-5$.

9 Rosenberg L, Miller DR, Kaufman DW, et al. Breast cancer and oral contraceptive use. Am $\mathcal{J}$ Epidemiol 1984;119:167-76.

10 Vessey MP, Baron J, Doll R, McPherson K, Yeates D. Oral contraceptives and breast cancer: final report of an epidemiological study. Brf Cancer 1983;47:455-62.

11 Stadel BV, Rubin GL, Webster LA, Schlesselman JJ, Wingo PA. Oral contraceptives and breast cancer in young women. Lancet 1985;ii:970-3.

12 Cancer and Steroid Hormone Study of the Centers for Disease Control and the National Institute of Child Health and Human Development. Oral contraceptive use and the risk of breas cancer. N Engl $\mathcal{3}$ Med 1986;315:405-11.

13 Anonymous. Another look at the pill and breast cancer [Editorial]. Lancet 1985;ii:985-7.

14 McPherson K, Coope PA. Early oral contraceptive use and breast cancer risk. Lancet 1986; 685-6.

15 Greenberg ER, Barnes AB, Resseguie L, et al. Breast cancer in mothers given diethylstilbestrol in pregnancy. $N$ Engl F Med 1984;311:1393-8.

16 McPherson K, Coope PA, Vessey MP. Early oral contraceptive use and breast cancertheoretical effects of latency. $\mathrm{Br} \mathcal{f}$ Epidemiol Community Health (in press)

17 Bone M. The family planning services: changes and effects. London: Office of Population Censuses and Surveys, 1978 .

18 Rothman KJ. Induction and latent periods. Am F Epidemiol 1981;114:253-9.

19 Bone M. Family planning in Scotland in 1982. Edinburgh: Scottish Home and Health Department, 1985.

20 Drife JO, Guillebaud JO. Hormonal contraception and cancer. Br f Hosp Med 1986;35:25-9.

21 Drife JO. The pill and the breast. International Planned Parenthood Federation Medical Bulletin $1984 ; 18(6): 1-2$.

\section{Arthroscopic surgery of the knee}

Just as the surgical replacement of joints has changed the practice of orthopaedic surgery in general, so arthroscopy has changed the character of knee surgery in particular. The lead came from surgeons in Japan in the 1960s, but interest in arthroscopy quickly spread to other countries. ${ }^{1.3}$ As surgeons gained experience of diagnostic arthroscopy those with a special interest in knee surgery began to devise ways of developing the arthroscope to enable them to carry out procedures within the joint. In England Dandy has pioneered these methods, which are steadily becoming established in specialist units. ${ }^{4}$ 
Arthroscopic surgery of the knee demands an exacting and skilled technique and a degree of patience and perseverence which is not a characteristic of every orthopaedic surgeon. A sound knowledge of diagnostic arthroscopy is needed before a surgeon moves on to operative arthroscopy. Once he has mastered the skills, however, there are considerable benefits for the patient - and his or her employer-and economic advantages for the NHS.

Early in the development of arthroscopy simple manoeuvres such as synovial biopsy, synovial shelf excision, or the removal of loose or foreign bodies from within the joint were found to cause little difficulty. More refined instruments made more complex operations possible. It is, however, the surgery of the menisci which has been altered most dramatically by the advent of operative arthroscopy. The technical innovations came at a time when a more conservative approach was developing towards excision of the menisci. Use of the operating arthroscope with new, stronger instruments allows the surgeon to deal with flap tears, bucket handle tears, tears of the anterior and posterior attachments, and other miscellaneous lesions without the need to open the joint extensively. Shaving and drilling of the patella and abrasion or drilling of chondral defects elsewhere in the knee are also possible. More complex procedures have been attempted, including fixing osteochrondral fragments, synovectomy for rheumatoid or haemophilic synovitis, ${ }^{5}$ total meniscectomy, and the endoscopic repair of peripheral meniscal detachments. Metcalf has categorised arthroscopically treatable lesions in a useful way, listing them in order of progressive difficulty from the surgeon's point of view. ${ }^{6}$

Most orthopaedic surgeons now accept that a meniscus should be removed only when it is known to be abnormal. ${ }^{7}$ Partial meniscectomy with removal of unstable fragments and preservation of as much of the meniscus as possible is the operation of choice, but it demands accurate diagnosis. A combination of clinical impression and arthroscopy can produce a diagnostic accuracy of $95 \%$, and when combined with arthrography this can be improved to $97 \% .^{8}$

Arthroscopic surgery has obvious advantages over open arthrotomy: these include preference by the patient and rapid rehabilitation and discharge from hospital. A study in 1984 of American soldiers showed a reduction of time in hospital of $32 \%$ with an annual saving to the army of over $\$ 5.5 \mathrm{~m} . .^{9}$ Average inpatient stays of between one day ${ }^{10}$ and two and a half days ${ }^{11}$ have been reported. As experience is gained some patients may be treated as day cases. The length of time taken off work in many reported series is in the region of 12 to 14 days compared with six to eight weeks or more after an open operation.

Complications of the procedure are remarkably few. In a series of 230 patients treated by surgeons of widely differing experience in whom open and arthroscopic meniscectomy was compared Simpson et al found no complications in the arthroscopic group; in the open group, on the other hand, there were two cases of deep venous thrombosis, two of haematoma, and one of wound dehiscence. ${ }^{12}$ Instruments may break, but the fragments may usually be retrieved arthroscopically. ${ }^{11}$ Infection after arthroscopy is almost unknown-and in view of the dubious sterility achieved during the procedure this is surprising to a degree which warrants further inquiry. ${ }^{5}$ Nevertheless, the greatest care must be taken to prevent contamination of instruments during surgery.

In the short term skilfully performed arthroscopic surgery can undoubtedly bring great therapeutic benefit. It remains to be seen, however, whether in the long term the procedure lives up to its early expectations in respect of meniscal surgery. This less destructive method of removing a troublesome fragment of meniscus may seem to be the best way, but, as Goodfellow has wisely pointed out, "It would be a pity if the liberty to operate by closed methods should be misinterpreted as a licence to operate too often." ${ }^{13}$ Only when patients who are being treated now by closed partial meniscectomy have been followed up for 20 years or more will it be known whether the long term risk has been avoided-osteoarthrosis after meniscal injury.

S C GALlanNAUGH

Consultant Orthopaedic Surgeon,

Royal East Sussex Hospital,

Hastings TN34 1ER

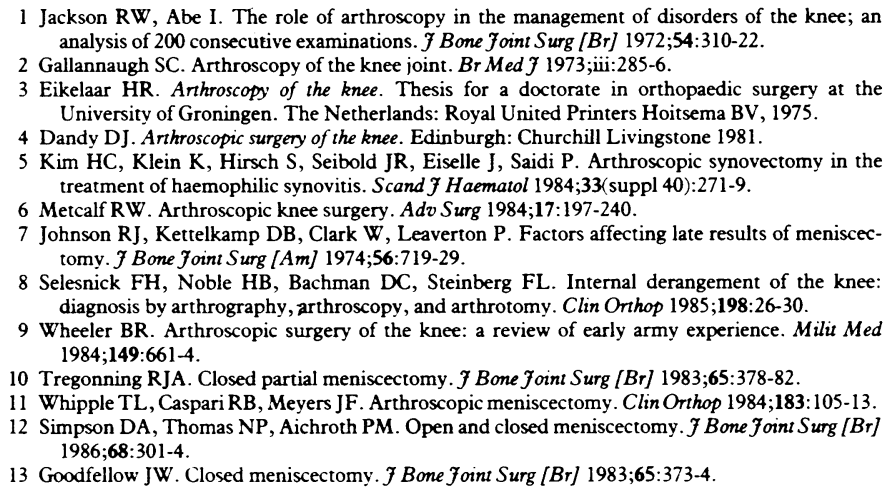

1 Jackson RW, Abe I. The role of arthroscopy in the management of disorders of the knee; an analysis of 200 consecutive examinations. F Bone foint Surg $[B r]$ 1972;54:310-22. analysis of 200 consecutive examinations. F Bone foint Surg (Br] 1972,54:3
Gallannaugh SC. Arthroscopy of the knee joint. Br Med f 1973;iii:285-6.

3 Eikelaar HR. Arthroscopy of the knee. Thesis for a doctorate in orthopaedic surgery at the University of Groningen. The Netherlands: Royal United Printers Hoitsema BV, 1975

Dandy DJ. Arthroscopic surgery of the knee. Edinburgh: Churchill Livingstone 1981.

5 Kim HC, Klein K, Hirsch S, Seibold JR, Eiselle J, Saidi P. Arthroscopic synovectomy in the treatment of haemophilic synovitis. Scand f Haematol 1984;33(suppl 40):271-9.

Metcalf RW. Arthroscopic knee surgery. Adv Surg 1984;17:197-240.

7 Johnson RJ, Kettelkamp DB, Clark W, Leaverton P. Factors affecting late results of meniscectomy. F Bone foint Surg $[\mathrm{Am}]$ 1974;56:719-29.

Selesnick FH, Noble HB, Bachman DC, Steinberg FL. Internal derangement of the knee: diagnosis by arthrography, arthroscopy, and arthrotomy. Clin Orthop 1985;198:26-30. Wheeler BR. Arthroscopic surgery of the knee: a review of early army experience. Milit Med 1984;149:661-4.

10 Tregonning RJA. Closed partial meniscectomy. I Bone foint Surg [Br] 1983;65:378-82.

11 Whipple TL, Caspari RB, Meyers JF. Arthroscopic meniscectomy. Clin Orthop 1984;183:105-13.

12 Simpson DA, Thomas NP, Aichroth PM. Open and closed meniscectomy. $\mathcal{F}$ Bone foint Surg [Br] 1986;68:301-4.

13 Goodfellow JW. Closed meniscectomy. F Bone foint Surg [Br] 1983;65:373-4

\section{Prenatal diagnosis of the Turner syndrome: what to tell the parents}

Each year in Britain there are over 23000 amniocenteses and these result in about 12 fortuitous diagnoses of the Turner syndrome. This number will rise as chorionic villus sampling is used more widely. What should the parents be told in such circumstances?

Most cases of the Turner syndrome are due to a missing sex chromosome to leave the constitution $45, \mathrm{X}$ or monosomy X. It is one of the commonest chromosomal disorders, occurring in about 150 of every 10000 conceptions. ${ }^{1}$ Most of these embryos abort spontaneously, however, and by the second trimester the incidence has fallen to 9 in every 10000 female fetuses in mothers over $35,{ }^{2}$ and by birth it is 1 in 10000 girls. ${ }^{3}$ The cause of this wastage is unknown but may relate to delayed opening of the jugular lymph sac into the jugular vein, which has normally occurred by 8 weeks' gestation. During the second trimester this may be apparent on an ultrasound scan as nuchal cystic hygromas and if associated with chlothorax and ascites carries a grave prognosis. ${ }^{4}$ An additional factor might be the placenta, which is typically hypoplastic with small hypervascular villi. ${ }^{5}$ The fetuses that survive may show neonatal sequelae of lymphatic obstruction with redundant neck skin or webbing, peripheral lymphoedema, deep set nails, and a predominance of finger tip whorls. $^{6}$

Congenital malformations are common in girls with the Turner syndrome: coarctation of the aorta or other congenital heart disease occurs in a fifth and a variety of usually 